\title{
STUDI KEMAMPUAN PANEL LVMDP TERHADAP PEMBEBANAN
}

\author{
M. Saleh Al Amin \\ Program Study Teknik Elektro Universitas PGRI Palembang \\ e-mail : saleh.pgri@gmail.com
}

\begin{abstract}
ABSTRAK Panel LVMDP merupakan peralatan listrik yang terdiri dari beberapa komponen listrik, yang berfungsi sebagai pembagi utama saluran distribusi tegangan rendah ke setiap saluran beban, sebagai pembatas daya utama, dan pengaman pada rangkaian utama sistem distribusi tegangan rendah. Komponen-komponen yang terdapat pada panel LVMDP ini antara lain, MCCB utama, MCCB salauran setiap beban atau cabang, Selector Switch, Contactor, KWh meter, ACB, UVT, OVT, OCR, EFR, RPR, GFCI, RCD, TOR, Busbar tembaga, CT, Alat ukur arus, tegangan, frekwensi, Faktor kerja, Synkronous meter, Capacitor Bank, Pushbutton, Pilot Lamp, dan peralatan penunjang lainnya, seperti terminal, dan lainnya. Komponen utama yang sangat berperan dalam penyaluran daya suatu panel LVMDP dalam keadaan normal adalah MCCB, yang dapat memikul seluruh beban panel dalam keadaan steady state. MCCB ini akan ditunjang oleh komponen-komponen lainnya apabila terjadi gangguan, seperti bila terjadi hubung singkat, yang terjadi setelah MCCB. Bila terjadi gangguan sebelum MCCB, maka komponen yang akan bekerja adalah UVT atau OVT, dan seterusnya, sehingga bila terjadi gangguan maka MCCB akan di backup oleh komponen penunjang. Tetapi bila terjadi kegagalan pada komponen penunjang, maka MCCB harus dapat berfungsi sebagai proteksi terhadap panel LVMDP secara keseluruhan, baik dari gangguan beban lebih, maupun gangguan hubung singkat, tetapi MCCB tidak dapat menanggulangi gangguan di luar kemampuannya. Dengan demikian kemampuan MCCB untuk melindungi panel LVMDP dari gangguan beban lebih dan hubung singkat, tertera pada nameplate MCCB tersebut.
\end{abstract}

Kata kunci : LVMDP, kemampuan MCCB

ABSTRACT In today's highly competitive industry, manufacturing and production industries are required to always be ready and reliable in the availability of products offered to consumers. This is absolutely absolute because ultimately it involves consumer satisfaction as the final part of a business chain. One of the factors that plays an important role in the industrial world is the facilities and facilities, facilities and facilities including production machinery, buildings, materials, and other supporting facilities. In this case the production machine is a vital part in a work / manufacturing location, where the production machine generally uses an electric motor as a driver in operating it. One type of electric motor that is widely used is the type of commutator induction motor, because according to their needs, namely for high speed, such as drilling machines, planers, mixers, which are the driving force of workshop and production equipment, which are often used in frame making workshops, workshops lathe, and other workshop. On continuous operation, only a few seconds of operation will stop, the motor coil will heat up, which means expansion of the coil wire. This will result in changes in motor impedance, so that the motor rotation will also change. The provisional guess of the test is that there is a expansion of coil wire due to heating, which results in an increase in motor impedance, so that the motor rotation will decrease

Keywords : LVMDP, $M C C B$

PENDAHULUAN

MCCB merupakan komponen utama yang sangat berperan dalam penyaluran daya suatu panel LVMDP, yang harus dapat memikul seluruh beban panel dalam keadaan steady state 
maupun gangguan. MCCB yang dipasang pada panel LVMDP juga harus mampu untuk menahan arus hubung singkat terbesar untuk seluruh rangkaian beban panel untuk jangka waktu tertentu.

Tetapi pada umumnya MCCB yang dipasang pada panel LVMDP tidak memperhitungkan kemampuan MCCB untuk menahan arus hubung singkat pada rangkaian bebannya, sehingga sering terjadi kerusakan MCCB pada panel LVMDP pada saat terjadi hubung singkat di rangkaian bebannya.

\section{TINJAUAN PUSTAKA}

\section{Panel LVMDP}

LVMDP adalah kependekan dari Low Voltage Main Distribution Panel, berarti panel LVMDP ini bekerja pada tegangan rendah dan berfungsi sebagai pembagi utama daya untuk seluruh instalasi feeder yang dilayaninya.

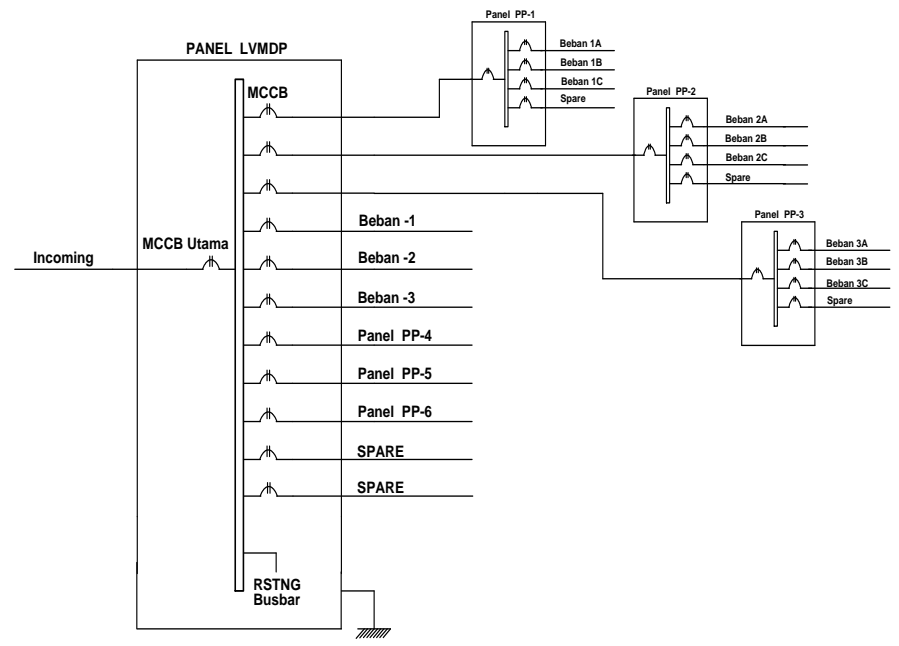

Gambar 1. Wiring Diagram Panel LVMDP sederhana.

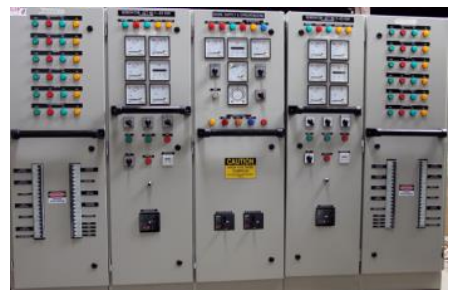

(a)

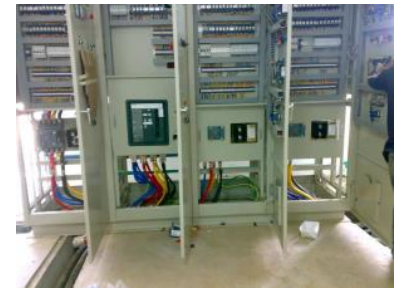

(b)

Gambar 2. Komponen LVMDP (a) di dalam panel (b) di luar panel

Dari Gambar 1, suatu wiring sistem kelistrikan panel LVMDP, komponen utama yang harus dapat memikul bebannya adalah MCCB utama, kemudian busbar, dan MCCB cabang. MCCB cabang harus dapat memikul setiap beban yang terdapat pada cabang pelayanannya 
(feeder). Sedangkan MCCB utama harus mampu memikul seluruh beban pada sistem kelistrikan yang dilayaninya.

Sedangkan busbar merupakan komponen pasif bagian dari suatu panel LVMDP, juga harus mampu memikul seluruh beban yang dilayani oleh panel LVMDP tersebut. Yang merupakan komponen pasif lainnya pada suatu panel adalah kabel penghubung antar komponen, dan schoon cable, tetapi kabel penghubung dan schoon cable tersebut telah dilakukan perhitungan tersendiri yang juga harus dapat memikul arus yang melaluinya.

\section{MCCB}

Merupakan singkatan dari Moulded Case Circuit Breaker, adalah komponen aktif yang dapat membatasi arus yang melaluinya, dan juga sebagai pemutus rangkaian. Ada beberapa kapasitas MCCB yang digunakan pada suatu panel, yaitu kapasitas tetap dan kapasitas bervariasi.

Untuk MCCB dengan kapasitas tetap, maka MCCB tersebut akan bekerja hanya pada kapasitas yang tertera pada nameplate MCCB tersebut, sedangkan untuk MCCB dengan kapasitas yang bervariasi, maka kapasitas kerja MCCB dapat di setting sesuai dengan nilai antara yang tertera pada nameplate MCCB tersebut.

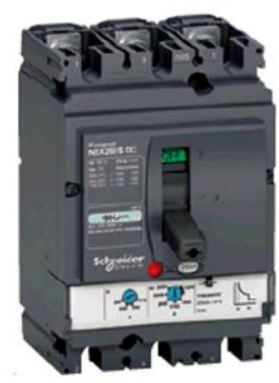

Gambar 4. Contoh sebuah MCCB

Disamping adanya kapasitas arus normal pada MCCB, terdapat juga kapasitas arus hubung singkat yang harus terpenuhi pada sebuah MCCB, dimana kapasitas arus hubung singkat tersebut merupakan besaran arus maksimum kejut sesaat yang masih mampu dipikul oleh MCCB sebelum terjadi pemutusan rangkaian. Besarnya kapasitas arus hubung singkat ini juga akan tertera pada nameplate MCCB.

Dalam pengoperasian $\mathrm{MCCB}$, pada saat terjadi pemutusan rangkaian, sama seperti $\mathrm{MCB}$, dapat dihubungkan kembali atau dapat ditutup rangkaianannya dengan cara manual, yaitu dengan tuas, dan dengan menggunakan otomatisasi dengan meggunakan sistem motorize. Sistem motorize ini juga dapat diopoerasikan secara manual dengan menggunakan pushbutton. 


\section{ATS (Automatic Transfer Switch).}

Penggunaan ATS pada panel LVMDP dapat dilakukan apabila digunakan sumber incoming lebih dari satu, seperti digunakan generator set (Genset) dan sistem Uninteruptable Power Suplay (UPS), yang dipasang pada sisi incoming LVMDP.

\section{KAPASITAS MCCB}

Kapasitas MCCB adalah total arus yang dapat melewati sebuah MCCB tanpa adanya hambatan dan masalah. Besarnya arus yang merupakan kapasitas dari sebuah MCCB tersebut adalah :

$$
\mathrm{I}_{\mathrm{kMCCB}}=\mathrm{I}_{\mathrm{bT}}+\mathrm{I}_{\mathrm{RJ}}
$$

Dimana :

$\mathrm{I}_{\mathrm{kMCCB}}=$ Kapasitas minimal arus MCCB, Ampere.

$\mathrm{I}_{\mathrm{bT}} \quad=\quad$ Arus beban tortal, Ampere.

$\mathrm{I}_{\mathrm{RJ}} \quad=\quad$ Arus yang disebabkan oleh rugi-rugi daya di jaringan, Ampere.

Dalam hal ini diasumsikan rugi-rugi daya sebesar $10 \%$.

Sedangkan kemampuan arus hubung singkat suatu MCCB, harus berada di atas arus gangguan hubung singkat yang mungkin terjadi dalam jaringan pelayanannya, yaitu :

$$
\mathrm{I}_{\mathrm{f} \mathrm{MCCB}}>\mathrm{I}_{\mathrm{ftJ}}
$$

Dimana :

$\mathrm{I}_{\mathrm{fMCCB}}=$ Kapasitas arus hubung singkat MCCB, Ampere.

$\mathrm{I}_{\mathrm{ftJ}} \quad=$ Arus hubung singkat pada jaringan pelayanan, Ampere.

\section{Arus Beban.}

a. Arus beban setiap feeder (cabang).

Arus beban untuk setiap feeder (cabang), dapat ditentukan dengan persamaan berikut :

$$
I_{b f}=\frac{P_{b f}}{V \cdot \cos (\varphi)}
$$

Dimana :

$\mathrm{I}_{\mathrm{bf}}=$ Arus yang mengalir di saluran beban setiap feeder (cabang), Ampere.

$\mathrm{P}_{\mathrm{bf}}=$ Daya beban per fasa tiap feeder (cabang), Watt.

$\mathrm{V}=$ Tegangan kerja beban per fasa, Volt.

$\cos (\varphi)=$ Faktor kerja beban.

b. Arus beban total.

Arus beban total, dapat ditentukan dengan persamaan berikut : 


$$
I_{b T}=\sum_{1}^{n} I_{b f(n)}
$$

Dimana :

$\mathrm{I}_{\mathrm{bT}}=$ Arus total yang harus dilayani MCCB, Ampere.

$\mathrm{I}_{\mathrm{bf}(\mathrm{n})}=$ Arus beban per fasa tiap feeder (cabang), Ampere.

\section{Arus Hubung Singkat.}

Untuk menentukan kapasitas arus hubung singkat suatu MCCB, digunakan standar arus hubung singkat fasa-fasa yang akan melalui MCCB tersebut pada saat gangguan. Diambil arus hubung singkat fasa-fasa, karena arus hubung singkat ini yang merupakan arus hubung singkat terbesar yang mungkin terjadi pada panel terdekat dari pelayanan panel LVMDP. Maka dari itu untuk gangguan dengan nilai arus terbesar adalah gangguan fasa-fasa, sehingga besarnya arus gangguan adalah sebagai berikut :

$$
\mathrm{I}_{\mathrm{f}(2 \mathrm{fasa})}=\frac{V_{f}}{Z_{1}+Z_{2}}
$$

Dimana :

$\mathrm{I}_{\mathrm{f}(\text { fasa })}=$ Arus gangguan 2 fasa, Ampere.

$\mathrm{V}_{\mathrm{f}} \quad=$ Tegangan saat gangguan, Volt.

$\mathrm{Z}_{1} \quad=$ Impedasi urutan positip, Ohm.

$\mathrm{Z}_{2} \quad=$ Impedasi urutan negatip, Ohm.

Impedansi urutan positip sama dengan negatip, dapat ditentukan dari saluran dan beban yang dilayani, dengan mengabaikan reaktansi saluran dan beban.

\section{METODE PENELITIAN}

Penelitian dilaksanakan di Stadion Bumi Sriwijaya Palembang, pada saat dilakukan perencanaan peningkatan pencahayaan lapangan, tribun, dan landscape stadion Bumi Sriwijaya Palembang tahun 2017.

\section{Kebutuhan data pendukung.}

a. Data daya beban tiap feeder.

b. Data impedansi urutan positip feeder dan beban.

c. Faktor kerja sistem.

d. Tegangan sistem.

e. Data sheet MCCB. 


\section{Menentukan Impedansi setiap feeder.}

Impedansi setiap feeder merupakan total impedansi seri saluran dan seri dengan impedansi paralel total beban. Untuk Stadion Bumi Sriwijaya memiliki lima (5) feeder beban yang masing-masing bermuara pada sebuah panel SDP, yaitu panel SDP-1 sampai dengan SDP-4 melayani masing-masing 60 buah lampu floodlight 2.000 watt, 380 volt, dan panel SDP5 yang melayani beban sistem kelistrikan stadion. Maka impedansi setiap feeder dapat ditentukan sebagai berikut :

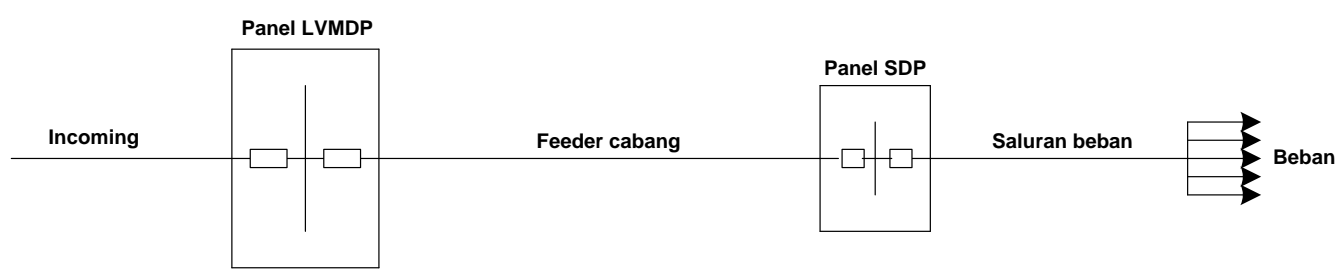

Gamb

Gambar 5. Diagram satu garis setiap feeder.

Dari gambar $5: \mathrm{Z}_{\mathrm{f}} \quad=\quad \mathrm{Z}_{\mathrm{fc}}+\mathrm{Z}_{\mathrm{sb}}+\mathrm{Z}_{\mathrm{b}}$

Dimana :

$\mathrm{Z}_{\mathrm{f}} \quad=$ Impedansi setiap feeder, Ohm.

$\mathrm{Z}_{\mathrm{fc}}=$ Impedansi feeder cabang, Ohm.

$\mathrm{Z}_{\mathrm{sb}}=$ Impedasi saluran beban, Ohm.

$\mathrm{Z}_{\mathrm{b}} \quad=$ Impedasi beban, Ohm.

\section{HASIL DAN PEMBAHASAN.}

\section{Data-data.}

Data-data beban dan saluran beban yang dilayani oleh panel SDP-1 adalah sebagai berikut :

- Lampu Floodlight $\quad$ : 2000 watt, 60 unit.

- Tegangan : 380 Volt.

- Kabel feeder, panjang : NYFGBY 4x95 mm, $330 \mathrm{~m}$.

- Kabel beban, panjang : NYY $3 \times 4 \mathrm{~cm}, 50 \mathrm{~m}$.

Data-data beban dan saluran beban yang dilayani oleh panel SDP-2 adalah sebagai berikut :

- Lampu Floodlight $\quad$ : 2000 watt, 60 unit.

- Tegangan : 380 Volt.

- Kabel feeder, panjang : NYFGBY 4x95 mm, $180 \mathrm{~m}$.

- Kabel beban, panjang : NYY $3 \times 4 \mathrm{~cm}, 50 \mathrm{~m}$. 
Data-data beban dan saluran beban yang dilayani oleh panel SDP-3 adalah sebagai berikut :

- Lampu Floodlight

- Tegangan

- Kabel feeder, panjang

- Kabel beban, panjang
: 2000 watt, 60 unit.

: 380 Volt.

: NYFGBY 4x95 mm, $150 \mathrm{~m}$.

: NYY $3 \times 4 \mathrm{~cm}, 50 \mathrm{~m}$.

Data-data beban dan saluran beban yang dilayani oleh panel SDP-4 adalah sebagai berikut :

- Lampu Floodlight

- Tegangan

- Kabel feeder, panjang

- Kabel beban, panjang
: 2000 watt, 60 unit.

: 380 Volt.

: NYFGBY 4x95 mm, $10 \mathrm{~m}$.

: NYY 3x4 mm, $50 \mathrm{~m}$.

Data-data beban dan saluran beban yang dilayani oleh panel SDP-5 adalah sebagai berikut :

- Beban

- Tegangan

- Kabel feeder, panjang
: $10 \mathrm{~kW}$.

: $380 / 220$ Volt.

: $\quad$ NYFGBY $4 \times 70 \mathrm{~mm}, 300 \mathrm{~m}$.

\section{Hasil Perhitungan Arus tiap Feeder.}

Berdasarkan pada formulasi pada persamaam (3) dan (4), maka diperoleh hasil perhitungan sebagai berikut :

Tabel 1. Hasil perhitungan arus beban setiap Feeder.

\begin{tabular}{|c|c|c|c|c|c|}
\hline No & $\begin{array}{c}\text { Beban } \\
\text { Panel }\end{array}$ & $\begin{array}{c}\text { Daya Total } \\
\text { (watt) }\end{array}$ & $\begin{array}{c}\text { Tegangan } \\
\text { Kerja (volt) }\end{array}$ & $\begin{array}{c}\text { Arus } \\
\text { (ampere) }\end{array}$ & $\begin{array}{c}\text { Arus total } \\
\text { (ampere) }\end{array}$ \\
\hline 1 & SDP-1 & 120.000 & 380 & 182 & \multirow{2}{*}{744} \\
\cline { 1 - 4 } 2 & SDP-2 & 120.000 & 380 & 182 & \\
\cline { 1 - 4 } 3 & SDP-3 & 120.000 & 380 & 182 & \\
\hline 4 & SDP-4 & 120.000 & 380 & 182 & \\
\hline 5 & SDP-5 & 10.000 & 220 & 16 & \\
\hline
\end{tabular}

Tabel 2. Hasil perhitungan arus hubung singkat setiap Feeder.

\begin{tabular}{|c|c|c|c|c|}
\hline No & Beban Panel & $\begin{array}{c}\text { Tegangan kerja } \\
\text { (volt) }\end{array}$ & $\begin{array}{c}\text { Impedansi urutan-1+2 } \\
\text { saluran }(\text { ohm })\end{array}$ & $\begin{array}{c}\text { Arus hubung singkat } \\
\text { (ampere) }\end{array}$ \\
\hline 1 & SDP-1 & 380 & 0,191070 & $1.151,5$ \\
\hline 2 & SDP-2 & 380 & 0,104220 & $2.110,9$ \\
\hline 3 & SDP-3 & 380 & 0,086850 & $2.533,1$ \\
\hline 4 & SDP-4 & 380 & 0,005790 & $37.996,5$ \\
\hline 5 & SDP-5 & 220 & 0,348300 & 631,6 \\
\hline
\end{tabular}




\section{Kapasitas MCCB.}

Berdasarkan pada hasil perhitungan yang diberikan pada tabel 1 dan tabel 2 , maka dapat ditentukan besarnya kapasitas MCCB yang digunakan sebagai MCCB utama pada panel LVMDP, yaitu :

\section{a. Kapasitas Arus MCCB.}

Dari tabel 1, arus beban total adalah 744 ampere. Rugi-rugi daya yang diasumsikan adalah $10 \%$ atau sebesar 74,4 ampere. Maka besarnya arus total yang akan mengalir pada MCCB adalah sebesar 818,4 ampere.

Maka kapasitas MCCB adalah $\geq 818,4$ ampere.

\section{b. Kapasitas Arus hubung singkat MCCB.}

Dari tabel 2, arus hubung singkat terbesar yaitu pada panel SDP-4 yaitu sebesar 37996,5 ampere, atau 37,9965 kA.

Maka kapasitas arus hubung singkat MCCB adalah $\geq 37,9965 \mathrm{kA}$.

Berdasarkan dari hasil perhitungan, kapasitas arus nominal MCCB pada suatu panel LVMDP sangat tergantung pada beban yang dilayaninya dan saluran feeder yang menghantarkan arus ke beban. Dari hasil perhitungan, kapasitas arus nominal MCCB adalah $\geq$ 818,4 ampere, yang berarti berarti nilai 818,4 ampere adalah kapasitas arus terendah dari MCCB yang dapat melayani bebannya. Tetapi sebaiknya dan dianjurkan untuk menggunakan MCCB dengan kapasitas arus $\geq 818,4$ ampere, sehingga akan terdapat spare arus untuk mengatasi fluktuasi beban dan switching.

Untuk kapasitas arus hubung singkatnya adalah sebesar 37,9965 kA, yang juga merupakan kapasitas terendah untuk mengatasi terjadinya hubung singkat di sisi bebannya agar MCCB tidak mengalami kerusakan. Tetapi sebaiknya dan dianjurkan agar digunakan MCCB dengan kapasitas $\geq 37,9965 \mathrm{kA}$, agar bila terjadi hubung singkat di sisi bebannya, MCCB akan aman dari kerusakan.

\section{KESIMPULAN.}

1. Kapasitas arus nominal MCCB berdasarkan perhitungan adalah $\geq 818,4$ ampere, dan penggunaan sebenarnya adalah kapasitas arus 1.000 ampere, dengan demikian MCCB akan aman dalam melayani bebannya.

2. Kapasitas arus hubung singkat berdasarkan perhitungan adalah $\geq 37,9965 \mathrm{kA}$, dan penggunaan sebenarnya adalah kapasitas arus hubung singkat $50 \mathrm{kA}$, dengan demikian MCCB akan aman bila terjadi gangguan hubung singkat.

3. Kapasitas MCCB utama tersebut merupakan kapasitas kemampuan panel LVMDP untuk melayani bebannya dalam kondisi normal dan gangguan hubung singkat. 


\section{DAFTAR PUSTAKA.}

1. Army TM 5-811-1, Air Force AFJMAN 32-1080,"'Electrical Power Supply and Distribution”, Dept of the Army, and the Air Force, USA, 1984.

2. Extrana Cable, "Product Catalogue " 2017.

3. James Northcote-Green, ABB Power Technology, "Control and Automation of Electrical Power Distribution System", Vasteras, Sweden, 2007.

4. PT. Inovasi Panel Usahatama, "Product Catalogue", 2017.

5. Schneider Electric, "Catalogue Numbers Simpact “ MCCB, 2016.

6. Schneider Electric, "Daftar Harga" 2017.

7. Zuhal. "Dasar Tenaga Listrik." Penerbit ITB, Bandung, 1991. 